Volume 11 Number 1 May 2021 Page. 11-16

Journal Homepage : http://teknois.stikombinaniaga.ac.id/index.php/JBS

DOI Link : http://doi.org/10.36350/jbs.v11i1

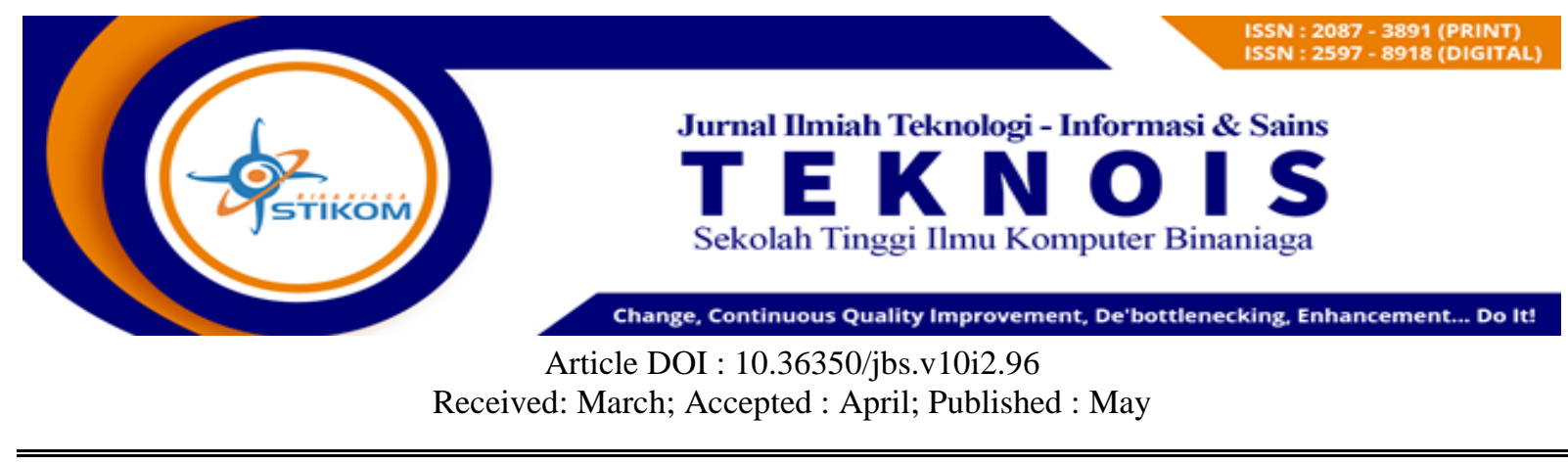

\title{
Penerapan Metode AHP untuk Memprediksi Pegawai Baru Department
} Store

\author{
Julio Warmansyah \\ Sistem Informasi/STIKOM Binaniga \\ Email: julio@stikombinaniaga.ac.id
}

\begin{abstract}
Companies engaged in the retail for staple foodstuffs, especially food, which have outlets evenly distributed throughout Indonesia. Requires a decision support system in an effort to improve the quality of the workforce that will be employed in widespread outlets. With so many workers who will be selected at this workforce recruitment, it requires a system that is able to provide support to companies in selecting many workers. By using the Process Hierarchy Analytical method, by analyzing the criteria for workers including Test Value, Education, Interview results, Distance between Rumam and the Store, with job titles and with 10 samples taken from the Cibinong area, Bogor district, this system provides assistance to HR in managing data to be analyzed on quite a lot of alternatives.
\end{abstract}

Keywords: AHP; Alternative; Criteria

\section{ABSTRAK}

Perusahaan yang bergerak dalam bidang retail kebutuhan bahan makanan pokok terutama pangan, yang memiliki gerai merata di seluruh Indonesia. Memerlukan system pendukung keputusan dalam upaya meningkatkan mutu tenaga kerja yang akan di pekerjakan pada gerai gerai yang tersebar luas. Dengan banyaknya pekerja yang akan di seleksi pada penerimaan tenaga kerja ini maka memerlukan system yang mampu memberi dukungan pada perusahaan dalam menyeleksi banyak pekerjanya. Dengan menggunaka metode Analitik Hirarki Proses, dengan menganalisa kriteria pekerja diantaranya adalah Nilai Test, Pendidikan, Hasil wawancara, Jarak Rumam ke tempat Gerai, dengan Jabatan pekerjaan dan dengan 10 sample yang di ambil dari area cibinong kabupaten Bogor System ini memberikan bantuan pada para SDM dalam mengelola data yang akan di analisis pada alternative yang cukup banyak.

Keywords: AHP; Alternatif; Kriteria.

\section{A. PENDAHULUAN}

\section{Latar Belakang}

Perusahaan retail besar yang memiliki gerai di berbagai daerah dan tersebar di pulau jawa Indonesia, melakukan perekrutan tenaga kerja berdasarkan distrik atau area tertentu. pada penelitian ini perekrutan di lakukan oleh kantor cabang ketenagakerjaan yang berada di cibinong kabupaten Bogor.

Karyawan yang akan di ambil terdapat pada gerai yang ada di wilayah Bogor kota, dengan kriteria pelamar berbagai macam. Untuk mendapatkan pelamar dengan kriteria yang sesuai maka pengolahan data yang telah masuk akan di terjemahkan dengan menggunakan angka agar dapat dihitung secara tepat. 
Volume 11 Number 1 May 2021 Page. 11-16

Journal Homepage : http://teknois.stikombinaniaga.ac.id/index.php/JBS

DOI Link : http://doi.org/10.36350/jbs.v11i1

Sebagai perusahaan yang bergerak dalam bidang retail makanan, yang memiliki gerai hampir seluruh kota besar di Indonesia, maka akan banyak pula tenaga kerja yang akan di pekerjakan pada gerai tersebut.

Dengan demikian akan ada system penilaian pada perekrutan tenaga kerja baru setiap perode sesuai dengan kebutuhan gerai yang selalu didirikan pada setiap kota dan daerah di Indonesia. Dengan banyaknya kebutuhan tersebut maka system penujang keputusan akan sangat penting dalam membantu penilaian secara obyektif hasil hasil penilaian sebelumnya.

\section{Rumusan Masalah}

Berdasarkan latar belakang diatas maka dapat diidentifikasi permasalahannya adalah sebagai berikut :

a. Belum adanya system pendukung keputusan untuk menentukan pegawai gerai.

b. Bagaimana penerapan Metode AHP dalam menentukan pegawai baru?

\section{Tujuan}

Adapun tujuan dari penelitian ini adalah menerapkan metode AHP untuk penentuan pegawai gerai.

\section{B. METODE}

Penelitian yang dilakukan adalah Penera Metode Analytic Hierarchy Process (AHP) Untuk Menentukan pemilihan karyawan pada perusahaan retail. Dengan menganalisa masalah yang ada dengan tujuan dasar membuktikan teori AHP. Adapun metode penelitian yang dilakukan dengan cara survey langsung pada Perusahaan tersebut, dan tahapan - tahapan yang dilakukan dalam proses pemecahan masalah adalah sebagai berikut:

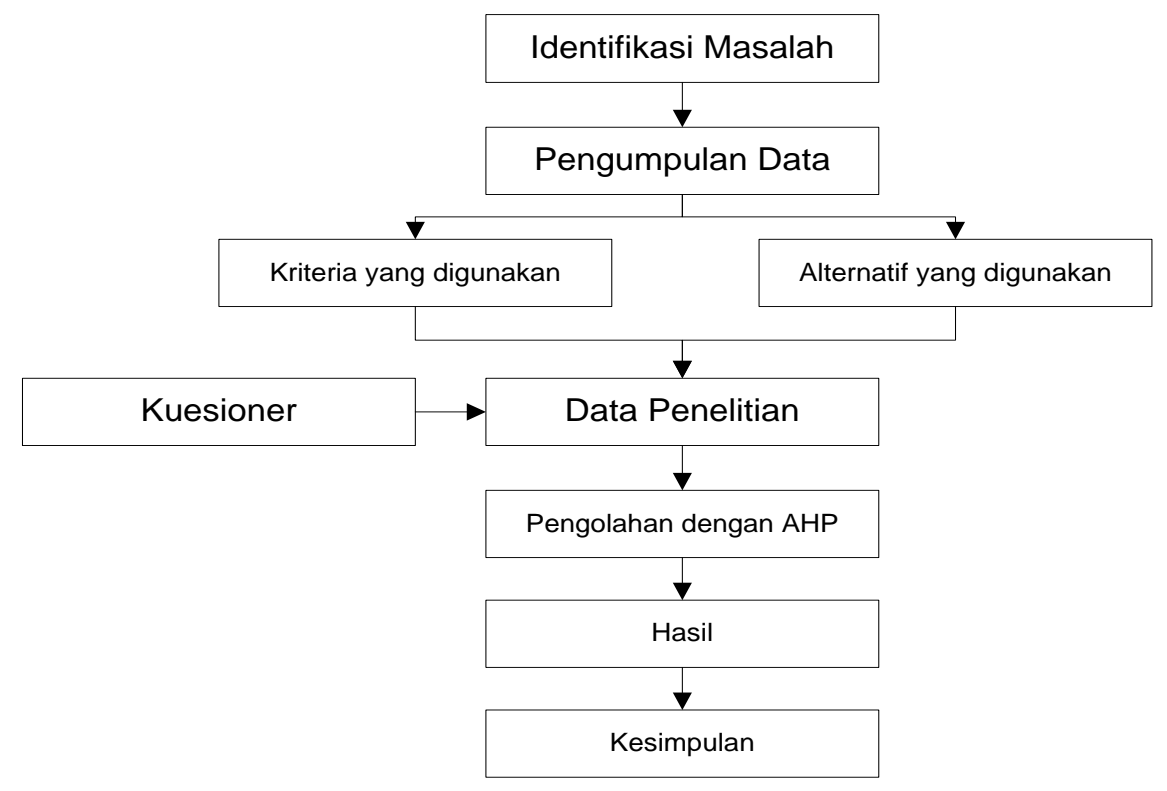

Gambar 1. Kerangka Penelitian

Metode penelitian menjelaskan tentang: pendekatan, ruang lingkup atau objek, definisi operasional variable/deskripsi fokus penelitian, tempat, populasi dan sampel/informan, bahan dan alat utama, teknik pengumpulan data, dan teknik analisis data.

\section{HASIL DAN PEMBAHASAN}

\section{HASIL}

Dengan menggunakan tabel yang telah di terjemahkan akan penilaian akan di hitung dengan mengambil nilai matrik pada penilaia masing - masing kriteria, yang akan di jadikan penilaia pada masing masing egenvektor yang akan di bentuk oleh pengkuadratan nilai dari nilai alternative.

Pada penilaian di bawah masing masing kriteria akan di nilai sesuai dengan kepentingan yang ada pada penilaian perbandingan jarak dengan dengan Pendidikan jarak dengan hasil tesr jarak 
Volume 11 Number 1 May 2021 Page. 11-16

Journal Homepage : http://teknois.stikombinaniaga.ac.id/index.php/JBS

DOI Link : http://doi.org/10.36350/jbs.v11i1

dengan jabatan Pendidikan dengan hasil test Pendidikan dengan jabatan dan hasil test dengan jabatan.

Tabel 1. Tabel uji masing - masing variable yang akan di uji

\begin{tabular}{|c|l|c|c|c|c|c|c|}
\hline No & Nama & JARAK & PDDK & HTES & JABATAN & NT & INT \\
\hline 1 & Fahrul rozi & 8 & 2 & 2 & 2 & 95 & 1 \\
\hline 2 & M riski ramadan & 4 & 1 & 2 & 2 & 85 & 200 \\
\hline 3 & Firdah niah & 3 & 1 & 0 & 1 & 50 & 200 \\
\hline 4 & Antika maulida & 1 & 2 & 2 & 1 & 95 & 200 \\
\hline 5 & Alpiah & 2 & 1 & 3 & 1 & 60 & 1 \\
\hline 6 & Fitria & 1 & 2 & 0 & 1 & 45 & 200 \\
\hline 7 & Sharania putri 1 & 9 & 1 & 2 & 1 & 50 & 200 \\
\hline 8 & Hesti marsita & 5 & 2 & 3 & 1 & 55 & 200 \\
\hline 9 & Vicky septiansyah k & 7 & 1 & 2 & 2 & 75 & 1 \\
\hline 10 & Syahrul septiawan & 6 & 2 & 0 & 2 & 80 & 200 \\
\hline
\end{tabular}

Proses selanjutnya adalah perbandingan masing masing kriteria sebagai variable hitung yang akan di masukan pada penilaian tabel terjemahan. Pengolahan data yang ada pada tabel hitung ini berdasarkan perbandingan yang di lakukan oleh ahli terhadap masing masing kriteria yang menjadi tolok ukur pada penilaian perekrutan karyawan baru. Dengan memberikan nilai perbandingan antara satu nilai kriteria dengan kriteria yang lain.

Tabel 2. Perbandingan Kriteria

\begin{tabular}{|l|r|r|r|r|r|r|}
\hline & \multicolumn{1}{|l|}{ Jarak } & Pddk & Htes & Jabatan & Nt & Int \\
\hline Jarak & 1,0000 & 0,5000 & 0,2857 & 1,0000 & 0,4000 & 0,2500 \\
\hline Pddk & 1,5000 & 1,0000 & 0,4286 & 1,5000 & 0,6000 & 0,3750 \\
\hline Htes & 3,5000 & 1,7500 & 1,0000 & 3,5000 & 1,4000 & 0,8750 \\
\hline Jabatan & 0,5000 & 0,2500 & 0,1429 & 1,0000 & 0,2000 & 0,1250 \\
\hline Nt & 2,5000 & 1,2500 & 0,7143 & 2,5000 & 1,0000 & 0,6250 \\
\hline Int & 4,5000 & 2,2500 & 1,2857 & 4,5000 & 1,8000 & 1,0000 \\
\hline
\end{tabular}

Pada penilaian diatas nilai akan di ambil berupa matrik dan akan di kwadratkan dengan hasil seperti tabel di bawah ini:

Tabel 3. Kwadran 1

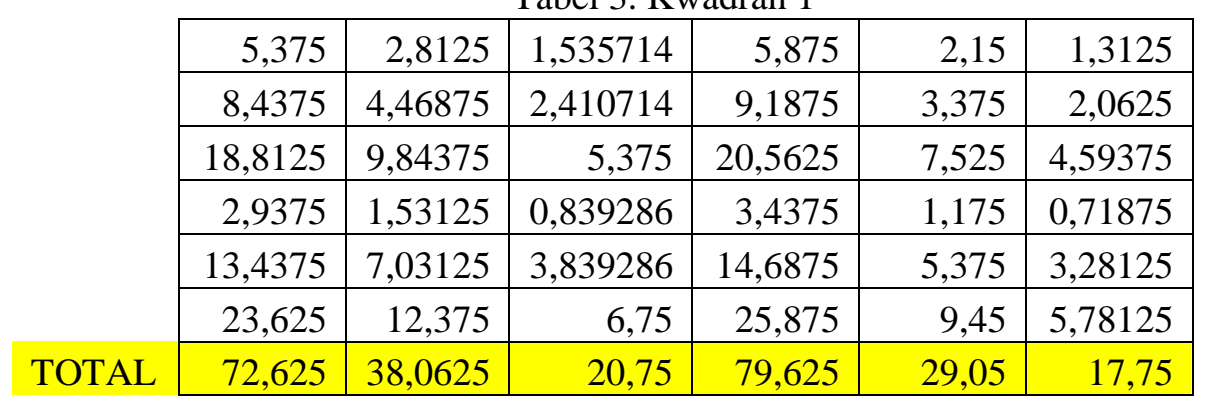

Untuk menormalisasi data yang di hasilkan pada tabel diatas maka jumlah dari masing masing kolom akan membagi nilai masing masing sel pada matrik tersebut dan akan tampak pada tabel berikut ini:

Tabel 4. Normalisasi

\begin{tabular}{|r|r|r|r|r|r|}
\hline 0,07401 & 0,073892 & 0,07401 & 0,073783 & 0,07401 & 0,073944 \\
\hline 0,116179 & 0,117406 & 0,116179 & 0,115385 & 0,116179 & 0,116197 \\
\hline 0,259036 & 0,258621 & 0,259036 & 0,258242 & 0,259036 & 0,258803 \\
\hline 0,040448 & 0,04023 & 0,040448 & 0,043171 & 0,040448 & 0,040493 \\
\hline
\end{tabular}


Volume 11 Number 1 May 2021 Page. 11-16

Journal Homepage : http://teknois.stikombinaniaga.ac.id/index.php/JBS

DOI Link : http://doi.org/10.36350/jbs.v11i1

\begin{tabular}{|l|l|l|l|l|l|}
0,185026 & 0,184729 & 0,185026 & 0,184458 & 0,185026 & 0,184859 \\
\hline 0,325301 & 0,325123 & 0,325301 & 0,324961 & 0,325301 & 0,325704 \\
\hline
\end{tabular}

Pada penilaian kedua tabel kwadrasi penilaian akan di lakukan kwadrasi kedua sehingga mengahasilkan egenvektor pertama dan kedua.

Tabel kwadrat kedua didapat dari nilai nilai pertama pada table

Tabel 5. Kwadran 2

\begin{tabular}{|c|c|c|c|c|c|c|}
\hline & \\
\hline & 158,668 & 83,1582 & 45,33371 & 174,7305 & 63,46719 & 38,77539 \\
\hline & 249,4746 & 130,7529 & 71,27846 & 274,7168 & 99,78984 & \\
\hline & 555,3379 & 291,0537 & & & 222,1352 & 135,7139 \\
\hline & 87,36523 & 45,78613 & 24,9615 & 96,25586 & 34,94609 & 21,35059 \\
\hline & 396,6699 & 207,8955 & 113,3343 & 436,8262 & 158,668 & 96,93848 \\
\hline & 697,957 & 365,8008 & & 768,6211 & 279,1828 & 170,5674 \\
\hline OTAL & 2145,473 & 1124,447 & 612,9922 & 2362,707 & 858,1891 & 524,3125 \\
\hline
\end{tabular}

Pada pernilaian normalisasi kedua nilai dari keseluruhan penilai nilai dari matrik perkolom dapat di jadikan seperti berikut:

Tabel 6 Noramalisasi 2

\begin{tabular}{|r|r|r|r|r|r|}
\hline 0,073955 & 0,073955 & 0,073955 & 0,073954 & 0,073955 & 0,073955 \\
\hline 0,11628 & 0,116282 & 0,11628 & 0,116272 & 0,11628 & 0,11628 \\
\hline 0,258842 & 0,258842 & 0,258842 & 0,258837 & 0,258842 & 0,258842 \\
\hline 0,040721 & 0,040719 & 0,040721 & 0,04074 & 0,040721 & 0,040721 \\
\hline 0,184887 & 0,184887 & 0,184887 & 0,184884 & 0,184887 & 0,184887 \\
\hline 0,325316 & 0,325316 & 0,325316 & 0,325314 & 0,325316 & 0,325316 \\
\hline
\end{tabular}

\section{PEMBAHASAN}

Pada perusahaan yang berbasis penjjualan kebutuhan pangan atau makanan yang tersebar di Indonesia. Perekrutan tenaga kerja silakukan bertahap diataranya pengumpulan berkas administrasi, pelaksanaan test dan wawancara. Pada tiga proses tersebut diputusnkan apakah calon tenaga kerja tersebut layak menjadi karyawan.

Ada dua jabatan yang menjadi penawaran perusahaan diantranya adalah kasir dan pramuniaga dan mempertimbangkan juga dengan jarak rumah tempat tinggal dengan tempat kerja.

Sehingga variable yang akan di uji menjadi dengan sebuah kriteria pada penilaian dengan menggunakan AHP (Analytical Hirarki Proses) adalah Pendidikan, nilai Test, Nilai dari interview, jabatan yang di tawarkan, dan jarak.

Tabel 7. Karyawan

\begin{tabular}{|r|l|l|r|l|l|l|l|}
\hline No & \multicolumn{1}{|c|}{ Nama } & Pend & Nilai Tes & Htes & Int & Jabatan & \multicolumn{1}{|c|}{ Jarak } \\
\hline 1 & Fahrul rozi & Smk & 95 & $\mathrm{P}$ & Nok & Pramu & Cilangkap \\
\hline 2 & M riski ramadan & Sma & 85 & $\mathrm{P}$ & Ok & Pramu & Cimanggis \\
\hline 3 & Firdah niah & Sma & 50 & $\mathrm{Tl}$ & Ok & Kasir & Ciampea \\
\hline 4 & Antika maulida & Smk & 95 & $\mathrm{P}$ & Ok & Kasir & Jasinga \\
\hline 5 & Alpiah & Sma & 60 & $\mathrm{~L}$ & Nok & Kasir & Cigudeg \\
\hline 6 & Fitria & Smk & 45 & $\mathrm{Tl}$ & Ok & Kasir & Jasinga \\
\hline 7 & Sharania putri 1 & Sma & 50 & $\mathrm{P}$ & Ok & Kasir & Cibinong \\
\hline 8 & Hesti marsita & Smk & 55 & $\mathrm{~L}$ & Ok & Kasir & Cilodong \\
\hline 9 & Vicky septiansyah & Sma & 75 & $\mathrm{P}$ & Nok & Pramu & Tapos \\
\hline 10 & Syahrul septiawan & Smk & 80 & $\mathrm{Tl}$ & Ok & Pramu & Gunung putri \\
\hline
\end{tabular}


Beberapa hal yang yang harus di terjemahkan dari penilaian kriteria diantaranya Pendidikan Hasil test, hasil dari hasil wawancara, jabatan yang akan di terima dan jarak yang akan di lihat dari paling dekat akan menghasilkan nilai paling tinggi dan di sajika pada tabel dibawah ini

Tabel 8. Interpretasi

\begin{tabular}{|l|l|l|}
\hline \multicolumn{3}{|c|}{ Hitung Tes } \\
\hline Kode & Keterangan & Skor \\
\hline TL & Tidak Lulus & 0 \\
\hline P & Pertimbangkan & 1 \\
\hline L & Lulus & 2 \\
\hline \multicolumn{3}{|c|}{ Interview } \\
\hline NOK & Not Ok & 1 \\
\hline OK & Ok & 2 \\
\hline \multicolumn{3}{|c|}{ Jabatan } \\
\hline Kasir & Kasir & 1 \\
\hline Pramu & Pramuniaga & 2 \\
\hline
\end{tabular}

Tabel 9. Konversi Jarak tempuh

\begin{tabular}{|c|c|}
\hline Tempat & Skor \\
\hline Jasinga & 1 \\
\hline Cigudeg & 2 \\
\hline Ciampea & 3 \\
\hline Cimanggis & 4 \\
\hline Cilodong & 5 \\
\hline Gunung Putri & 6 \\
\hline Tapos & 7 \\
\hline Cilangkap & 8 \\
\hline Cibinong & 9 \\
\hline
\end{tabular}

Tabel jarak ini berubah ubah sesuai dengan kebutuhan karyawan pada cabang tertentu dengan lokasi yang berbeda di seluruh Indonesia, hal ini untuk memudahkan karyawan dekat dengan tempat tinggal yang ada pada saat itu. Pengukuran yang terjadi adalah berbanding terbalik dengan jarak sebenarnya, semakin rangking kecil maka jarak tempuh semakin besar, dan mengurangi penilaian yang akan di langsungkan pada saat tersebut. Hasil terjemahan akan menjadi tabel uji pada tampak pada tabel 1 . Tabel yang telah di terjemahkan baru dapat di uji dengan menggunakan AHP.

Penilaian yang di hasilkan pada kwadrasi pertama dan kedua akan menghasilkan egn vector pertama dan kedua diantaranya adalah

$\begin{array}{ccc}\text { EIGEN VEKTOR } 2 & \text { EIGEN VEKTOR 1 } & \text { CR } \\ 0,443727331 & 0,443649628 & 0,0001 \\ 0,697672184 & 0,697524387 & 0,0001 \\ 1,553045659 & 1,552773699 & 0,0003 \\ 0,24434177 & 0,24523647 & -0,0009 \\ 1,109318328 & 1,10912407 & 0,0002 \\ 1,951894728 & 1,951691746 & 0,0002\end{array}$

Menghasilkan nilai yang kecil artinya nilai yang dihasilkan dapat di pakai untuk menilai alternative pada masing masing calon tenaga kerja yang akan di angkat menjadi karyawan pada perusahaan

\begin{tabular}{|c|l|c|c|c|c|c|c|}
\hline \multicolumn{1}{|c|}{ Tabel 10. Hasil } \\
\hline No & Nama & Jark & Pend & Htes & Jbtn & Nt & Int \\
\hline 1 & Fahrul rozi & 8 & 2 & 2 & 2 & 95 & 1 \\
\hline 2 & M riski ramadan & 4 & 1 & 2 & 2 & 85 & 200 \\
\hline
\end{tabular}

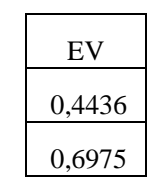

\begin{tabular}{|c|c|}
\hline Hasil & Rank \\
\hline 115,8587 & 8 \\
\hline 490,682 & 2 \\
\hline
\end{tabular}


Volume 11 Number 1 May 2021 Page. 11-16

Journal Homepage : http://teknois.stikombinaniaga.ac.id/index.php/JBS

DOI Link : http://doi.org/10.36350/jbs.v11i1

\begin{tabular}{|c|c|c|c|c|c|c|c|c|c|c|c|c|}
\hline 3 & Firdah niah & 3 & 1 & 0 & 1 & 50 & 200 & \multirow[b]{2}{*}{$X$} & 1,5529 & \multirow[b]{2}{*}{$=$} & 448,0683 & 6 \\
\hline 4 & Antika maulida & 1 & 2 & 2 & 1 & 95 & 200 & & 0,2452 & & 500,8946 & 1 \\
\hline 5 & Alpiah & 2 & 1 & 3 & 1 & 60 & 1 & & 1,1091 & & 74,98752 & 10 \\
\hline 6 & Fitria & 1 & 2 & 0 & 1 & 45 & 200 & & 1,9516 & & 442,3329 & 7 \\
\hline 7 & Sharania putri 1 & 9 & 1 & 2 & 1 & 50 & 200 & & & & 453,8357 & 5 \\
\hline 8 & Hesti marsita & 5 & 2 & 3 & 1 & 55 & 200 & & & & 459,857 & 4 \\
\hline 9 & Vicky septiansyah & 7 & 1 & 2 & 2 & 75 & 1 & & & & 92,53509 & 9 \\
\hline 10 & Syahrul septiawan & 6 & 2 & 0 & 2 & 80 & 200 & & & & 483,6157 & 3 \\
\hline
\end{tabular}

Dengan demikian akan tampil penilaian dari masing masing karyawan dengan urutan yang rangking pada masing masing calon karyawan.

\section{KESIMPULAN}

Penilaian untuk perekrutan tenaga kerja untuk karyawan pada perusahaan swalayan dengan kriterian Jarak dari para pelamar. Dimana Antika Maulida mendapat urutan pertama M Rizki Ramadan menjadi urutan kedua Syahrul Septiawan menjadi urutan 3 Hesti Marsita menjadi urutan ke 4 sampai dengan Alpiah menjadi urutan ke10 pada perekrutan tenaga kerja, Pendidikan yang di tempuh para pelamar kerja, Hasil test yang telah perusahaan lakukan pada para pelamar kerja, jabatan yang kosong pada perusahaan dan nilai interview pada karyawan yang telah dinilai dengan pembulatan 1-200. Hal tersebut diatas dapat membuktikan penilaian AHP dapat di lakukan pada berbagai kriteria yang telah di terjemahkan terlebih dahulu menjadi nilai dan dapat pembandingkan penilaian tersebut menjadi sebuah ranking prioritas pada perekrutan tenaga kerja yang memiliki variative variable

\section{E. DAFTAR PUSTAKA}

[1] Hijriani, A., Chandra, A., Hardiansyah, N., \& Riki, T. A. (2013). Seminar Nasional Sains \& Teknologi V Lembaga Penelitian Universitas Lampung 19-20 November 2013. Seminar Nasional Sains \& Teknologi V, (November), 84-95

[2] Kusrini, 2007. Konsep dan Aplikasi Sistem Pendukung Keputusan. Andi, Yogyakarta.

[3] Maya, P., \& Laksono, M. S. (2011). Analisa dan perbaikan sistem evaluasi kelayakan pengambilan kredit di bank syariah x. Prosiding Seminar Nasional Manajemen Teknologi XIII, (Pebruari).

[4] Mulyadi, Dedy, and Desy R. Marpaung. "Penerapan Metode Analytical Hierarchy Process (Ahp) Untuk Penentuan Kolektor Terbaik Pada PT. Anugrah Argon Medica Bogor." Teknois, vol. 8, no. 1, May. 2018, pp. 61-77, doi:10.36350/jbs.v8i1.21.

[5] Saragih, S. H. (2013). PENERAPAN METODE ANALITYCAL HIERARCHY PROCESS ( AHP ) PADA SISTEM PENDUKUNG KEPUTUSAN PEMILIHAN LAPTOP. Pelita Informatika Budi Darma, VI(Agustus), 82-88.

[6] Soepardi, A., Chaeron, M., \& Anggraini, I. (2012). Penentuan Kriteria Pemilihan Strategi Sistem Manufaktur Menggunakan Analytic Hierarchy Process, 14(2), 107-114

[7] Supriyatna, Alam. "Optimalisasi Penentuan Supplier dengan Pendekatan Metode AHP." Teknois, vol. 6, no. 2, Nov. 2016, pp. 1-11, doi:10.36350/jbs.v6i2.36.

[8] Utari, Lis, and Bobby S. Aprilian. "Pemilihan Titik Strategis untuk Pemasangan Reklame Produk Rokok di Kecamatan Cibinong Kabupaten Bogor Menggunakan Metode Fuzzy Analytical Hierarchy Process (F-AHP)." Teknois, vol. 8, no. 1, May. 2018, pp. 29-47, doi:10.36350/jbs.v8i1.19. 